\title{
Selective Polymerization of 2-Isopropenyl-2-oxazoline and Cross-linking Reaction of the Polymers
}

\author{
Tsutomu Kagiya and Takehisa Matsuda \\ Department of Hydrocarbon Chemistry, Faculty of Engineering, \\ Kyoto University, Yoshida, Kyoto, Japan.
}

(Received July 17, 1971)

\begin{abstract}
The selective polymerization of 2-isopropenyl-2-oxazoline possessing two polymerizable sites in molecule was studied. Due to a marked difference in polymerizability between the isopropenyl and oxazoline groups, this monomer provided soluble linear polymers by radical and cationic polymerization. The former was poly(2-isopropenyl-2-oxazoline) with the oxazoline group as a side chain, and the latter $N$-methacryloyl polyethylenimine. The cross-linking reactions of reactive pendant groups in both polymers, which resulted from the radical and cationic polymerizations, gave cross-linked, insoluble products.
\end{abstract}

KEY WORDS Difunctional Monomer / 2-Isopropenyl-2-oxazoline /

Selective Polymerization / Poly(2-isopropenyl-2-oxazoline) / N-Meth-

acryloyl Polyethylenimine / Cross-linking Reaction / Gelation /

2-Isopropenyl-2-oxazoline is a difunctional monomer possessing an isopropenyl group and oxazoline heterocycle as the polymerizable sites in molecule. It is reported by T. Kagiya, et al. ${ }^{1}$ and several other investigators ${ }^{2-5}$ that 2-oxazolines can be polymerized by cationic catalysts such as stannic chloride or boron trifluoride etherate to give $N$-acyl or $N$-aryloyl polyethylenimine. Kagiya, et al., ${ }^{6}$ reported that 2-isopropenyl-2-oxazoline gave poly(2-isopropenyl-2oxazoline) by radical vinyl polymerization.

The purpose of this paper is to report the selective cationic and radical polymerization of 2-isopropenyl-2-oxazoline, and the cross-linking reaction of the linear polymer having a polymerizable functional group as pendant side chain.

\section{EXPERIMENTAL}

\section{Material}

$\mathrm{N}$-Methacryloylethylenimine was prepared from the Schotten-Baumann reaction of ethylenimine and methacryloyl chloride in acetone media at $-30^{\circ} \mathrm{C}$, according to the method of Watanabe, et al. ${ }^{7}$ 2-Isopropenyl-2-oxazoline (IPOZ) was obtained from the isomerization reaction of $N$-methacryloylethylenimine with the use of sodium iodide as catalyst at $60^{\circ} \mathrm{C}$ for 15 hours according to the literature, ${ }^{8}$ and purified by careful distillation under reduced pressure [bp $\left.50.5^{\circ} \mathrm{C}(17.5 \mathrm{~mm})\right]$. The identification was carried out by the infrared and NMR spectra of the product.

Adipic acid as a cross-linker and $\alpha, \alpha^{\prime}$-azobisisobutyronitrile (AIBN), which were commercially available products (G. R. Grade reagents), were used without further purification.

\section{Oxazolinium Perchlorate}

Perchloric acid (70-\% aqueous solution) ought not to be used as an initiator in the cationic polymerization of 2-oxazolines, because 2-oxazolines can be readily hydrolyzed. ${ }^{9}$ The oxazolinium perchlorates of 2-isopropenyl-2oxazoline and 2-phenyl-2-oxazoline as cationic initiators were prepared in the same manner as previously described. ${ }^{11}$ The perchlorate salt of poly(2-isopropenyl-2-oxazoline) (Poly-IPOZ) was prepared by the same manner as above. From the elementary analysis and infrared spectrum, the following polyfunctional oxazolinium perchlorates were identified.

Perchlorate salt of 2-isopropenyl-2-oxazoline $\left(\mathrm{IPOZ}-\mathrm{HClO}_{4}\right), \mathrm{mp} 98.5-99.0^{\circ} \mathrm{C}$.

Anal. Calcd: C, 32.40; N, 6.28; Cl, 16.41 . Found: C, 32.16; N, 6.19; Cl, 16.53. Perchlorate salt of 2-phenyl-2-oxazoline (POP), 
Anal. Calcd: C, 43.64; N, 5.71; Cl, 14.36. Found: C, 43.68; N, 5.65; Cl, 14.42 . Complete perchlorate salt of Poly-IPOZ (A)

Anal. Calcd: C, 32.40; N, 6.28; Cl, 16.41 . Found: C, 32.66; N, 6.25; Cl, 16.40 . Partial perchlorate salt of Poly-IPOZ (B)

Anal. Found: C, 58.41; N, 1.1.38; Cl, 3.29.

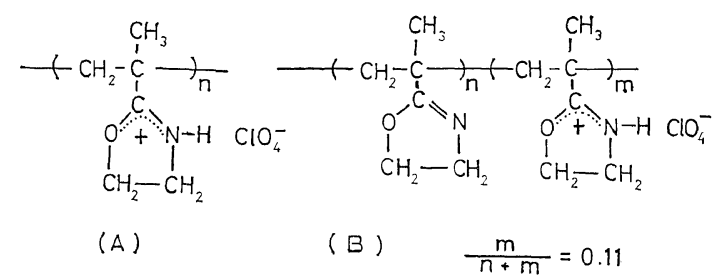

\section{Polymerization}

Polymerizations were carried out in sealed ampoules. The ampoule sealed under high vacuum after several freeze-evacuate-thaw cycles was allowed to stand in the thermostat at the required temperature and poured into excess $n$-hexane after a given polymerization period. The radical polymerization of IPOZ and copolymerization with methacrylic acid were carried out in bulk at $60^{\circ} \mathrm{C}$ in the presence of $1 \mathrm{~mol} \%$ of AIBN as radical initiator to monomer $\left(1.8 \times 10^{-2} \mathrm{~mol}\right)$. The cationic polymerization of IPOZ $\left(1.8 \times 10^{-2} \mathrm{~mol}\right)$ was carried out at $70-125^{\circ} \mathrm{C}$ in the dark in $N, N$-dimethylacetamide $(3.0 \mathrm{ml})$ including $1 \mathrm{~mol} \%$ of hydroquinone and $1 \mathrm{~mol} \%$ of catalyst with respect to monomer.

\section{Post-reactions of Linear Polymers Resulted from} the Selective Polymerization

\section{(A) Cross-linking Reactions of Poly-IPOZ}

The ring-opening addition reactions of $0.50 \mathrm{~g}$ of Poly-IPOZ and a definite amount of butyric acid or adipic acid in $3.0 \mathrm{ml}$ of $N, N$-dimethylacetamide were carried out in sealed ampoules degassed in vacuo. The residual product not extracted by hot methanol and the methanolsoluble fraction reprecipitated by $n$-hexane were dried in vacuo, and weighed. The gel fraction was calculated from the ratio of the weight of the insoluble part to that of initial polymer. The gelation time was measured visually from the observation of the change of the reaction system from the sol state to the gel state. The cationic polymerization of Poly-IPOZ was carried out in the same manner as described above.

(B) Radical Cross-linking Reaction of N-Methacryloyl Polyethylenimine

The radical polymerization of $N$-methacryloyl polyethylenimine $(1.50 \mathrm{~g})$ was carried out in $N, N$-dimethylacetamide $(5.0 \mathrm{~m} l)$ with the use of AIBN $(25 \mathrm{mg})$ as radical initiator at $60^{\circ} \mathrm{C}$ according to the same method as described above.

Physical Analyses of Linear Polymers Formed by Selective Polymerization and the Product of the Post-reaction

The infrared absorption spectra of the $\mathrm{KBr}$ pellets of the polymers were obtained by using an infrared spectrophotometer, model DS-403G, of the Japan Spectroscopic Co., Ltd.

The nuclear magnetic resonance spectra were measured by a Varian $\mathrm{H}-100$ Spectrometer (100 $\mathrm{MHz}$, with tetramethylsilane as an internal standard at room temperature.

The melting point was measured visually under nitrogen atmosphere in a capillary with a Yanagimoto melting point measuring apparatus, Model MP-S2, equipped with a microscope $(\times 10)$.

The intrinsic viscosity measurements were made in chloroform at $35^{\circ} \mathrm{C}$ with the use of an Ubbelohde viscometer.

\section{RESULTS AND DISCUSSION}

\section{Radical Polymerization of 2-Isopropenyl-2-oxa- zoline}

The polymer (Poly-IPOZ) of 2-isopropenyl-2oxazoline (IPOZ) formed by the radical initiator is a white powdery solid soluble in chloroform, methanol and $N, N$-dimethylacetamide, but insoluble in diethyl ether and hydrocarbon solvents such as $n$-hexane. The infrared spectrum of the polymer shows the characteristic absorption peaks attributed to oxazoline heterocycle $[\mathrm{C}=\mathrm{N}$ stretching vibration; $\nu_{\mathrm{C}=\mathrm{N}}=1655 \mathrm{~cm}^{-1}$, the ether stretching vibrations; $\nu_{\mathrm{C}-\mathrm{O}}=1278 \mathrm{~cm}^{-1}$ (conjugated with isopropenyl group) and $1137 \mathrm{~cm}^{-1}$ (uncojungated) and ring skeletal vibrations; $\nu_{r, s}=991,958$ and $930 \mathrm{~cm}^{-1}$ ], whereas the characteristic absorption band assignable to the isopropenyl group (conjugated with $\mathrm{C}=\mathrm{N}$ ) at $1610 \mathrm{~cm}^{-1}$ and the ether group conjugated with isopropenyl group at $1278 \mathrm{~cm}^{-1}$ disappeared, as 


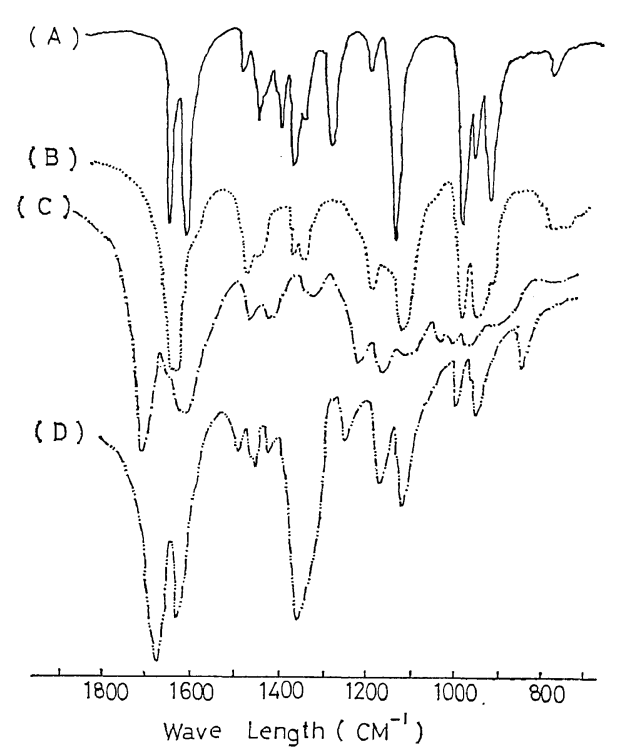

Figure 1. The infrared spectra of 2-isopropenyl-2oxazoline and the polymers resulting from radical and cationic polymerization: (A) 2-isopropenyl2-oxazoline; (B) the polymer formed by radical polymerization; (C) the polymer formed by cationic polymerization; (D) $\mathrm{N}$-methacryloylethylenimine.

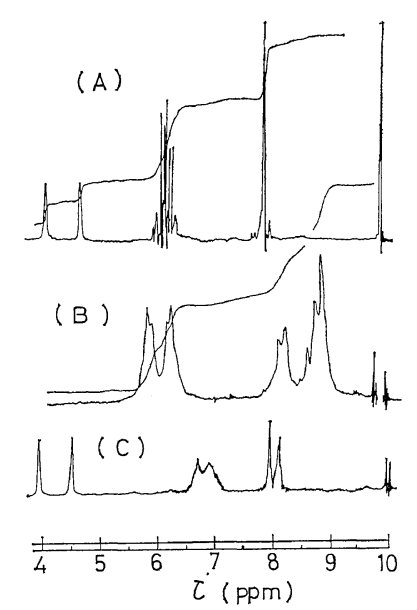

Figure 2. The NMR spectra of 2-isopropenyl-2-oxazoline and the polymers resulting from radical and cationic polymerization: (A) 2-isopropenyl-2-oxazoline; (B) the polymer formed by radical polymerization; (C) the polymer formed by cationic polymerization; $10-\%$ chloroform solution; room temperature; $100 \mathrm{Mc} / \mathrm{sec}$; tetramethylsilane as an internal standard. shown in Figure 1. An NMR spectrum of the polymer (Figure 2) displays the ethylenic protons of the oxazoline heterocycle in the neighborhood of $5.7-6.5 \tau$, the methylene unit at $8.1 \tau$ and the triplet due to the methyl protons at 8.6-9.0 $\tau$. The integration of these resonance peaks gives the proton ratio of 3 (methyl): 2 (methylene): 4 (ring methylene) which is consistent with the following structure.<smiles>C=C(C)C1=NCCO1</smiles>

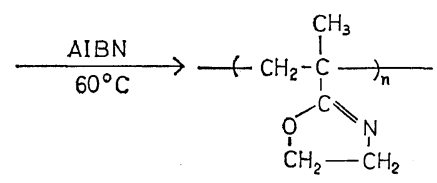

From these observations it is concluded that IPOZ converts to poly(2-isopropenyl-2-oxazoline) (Poly-IPOZ) with the oxazoline heterocycle as a reactive pendant side chain by radical polymerization.

Post-reactions of Poly(2-isopropenyl-2-oxazoline) (Poly-IPOZ)

The linear polymer (Poly-IPOZ) resulting from the radical polymerization of IPOZ was subjected to various post-reactions of the pendant oxazoline group capable of subsequent reactions. By use of the chemical reactivity and polymerizability of the 2-oxazoline group in the polymer, the following cross-linking reactions $[(\mathrm{A})$ and (B)] of Poly-IPOZ were carried out.

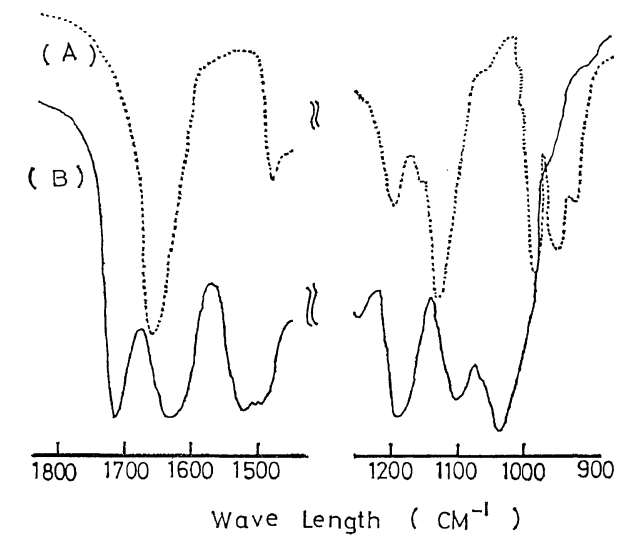

Figure 3. The infrared spectrum of the ring-opening addition product of Poly-IPOZ with butyric acid: (A) the polymer (Poly-IPOZ) formed by the radical polymerization of 2-isopropenyl-2-oxazoline; (B) the product from the ring-opening addition reaction of Poly-IPOZ with butyric acid. 
(A) Cross-linking Reactions of Poly(2-Isopropenyl-2-oxazoline) with Polyfunctional Carboxylic Acid

It is known that 2-oxazolines give straight chain derivatives of an amide-ester linkage by the ring-opening addition reaction with carboxylic acid at considerably high temperature. ${ }^{10}$ The equimolar mixture of Poly-IPOZ and butyric acid at $150^{\circ} \mathrm{C}$ in $N, N$-dimethylacetamide gave a white powdery solid melted at $210^{\circ} \mathrm{C}$. A comparison of the infrared spectrum of the initial polymer (Poly-IPOZ) and that of the product disclosed the disappearance of the characteristic absorptions of the oxazoline heterocycle and the subsequent appearance of a peak at $1720 \mathrm{~cm}^{-1}$ assignable to an ester linkage and two peaks at 1640 and $1545 \mathrm{~cm}^{-1}$ attributable to a secondary amide linkage (Figure 3). The above observation indicates that the oxazoline group as the pendant side chain of Poly-IPOZ reacts with butyric acid to give the side chain of an amide-ester linkage as follows.

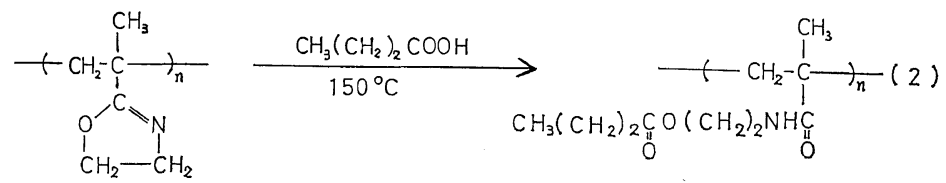

By the ring-opening addition reactions of Poly-IPOZ with adipic acid in $N, N$-dimethylacetamide, the gelations of the polymer solution were observed as shown in Table I. The residue not extracted by hot methanol was an insoluble, infusible polymer which decomposed over $280^{\circ} \mathrm{C}$. The observed gelation time, as shown in Table I, increases with a decrease in the reaction temperature and in the initial molar ratio of the carboxyl group of used adipic acid to the oxazoline group of Poly-IPOZ. These observations lead to the conclusion that the ring-opening reaction of Poly-IPOZ with adipic acid gives a network polymer with the following

Table I. The cross-linking reactions of poly(2-isopropenyl-2-oxazoline) with polyfunctional carboxylic acids ${ }^{a}$

\begin{tabular}{cccccccc}
\hline \multirow{2}{*}{ Run no. } & \multicolumn{2}{c}{ Reactants } & {$[\mathrm{C}] /[\mathrm{O}]^{\mathrm{b}}$} & $\begin{array}{c}\text { Reaction } \\
\text { temp, }{ }^{\circ} \mathrm{C}\end{array}$ & Appearance & $\begin{array}{c}\text { Gelation } \\
\text { time, } \\
\text { min }\end{array}$ & $\begin{array}{c}\text { Gel } \\
\text { fraction, } \\
\text { wt } \%\end{array}$ \\
\hline 1 & & 0.05 & 150 & & 15.4 & 12.2 \\
2 & & & 0.20 & 150 & & 7.4 & - \\
3 & & 0.50 & 150 & & 5.8 & - \\
4 & Poly-IPOZ $^{\mathrm{c}}$ & Adipic acid & 0.20 & 110 & Gel & 58.3 & - \\
5 & & & 0.20 & 120 & & 21.0 & 4.3 \\
6 & & & 0.20 & 130 & & 18.2 & - \\
7 & & & 0.20 & 140 & & 12.1 & - \\
\hline 8 & IPOZ $^{\text {d }}$ & Methacrylic & 1.00 & 70 & Sol & - & - \\
90 & & acid & 1.00 & 70 & Gel & - & - \\
\hline
\end{tabular}

a All reactions were carried out in $N, N$-dimethylacetamide $(3.0 \mathrm{~m} l)$. The used Poly-IPOZ and IPOZ were $0.50 \mathrm{~g}$ and $1.00 \mathrm{~g}$, respectively.

b The initial molar ratio of the carboxyl group [C] in used polyfunctional carboxylic acid to the oxazoline group [O] in polymer.

c Poly(2-isopropenyl-2-oxazoline) resulting from radical polymerization of IPOZ monomer.

a IPOZ denotes 2-isopropenyl-2-oxazoline.

e In run no. 8-9, the radical copolymerizations were carried out for $15 \mathrm{~min}$ and about $4 \mathrm{hr}$, respectively, with the use of AIBN as initiator. The conversion was about $5 \mathrm{wt} \%$ in run no. 8 , and about $80 \%$ in run no. 9 , respectively. 
cross-linking unit of two amide and two ester where $\mathrm{A}=$ linkages.

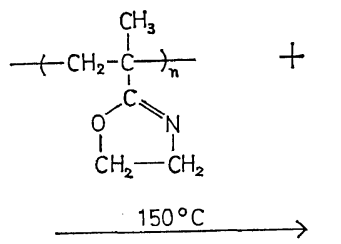

$\mathrm{HOOC}\left(\mathrm{CH}_{2}\right)_{4} \mathrm{COOH}$

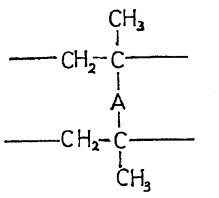

( 3 )<smiles>CC(=O)NCCO[Ge](=O)CC(=O)OCCNC=O</smiles>

The radical copolymerization of IPOZ monomer with methacrylic acid gave a soluble linear copolymer at low conversion, whereas an insoluble, infusible cross-linked copolymer was obtained at a higher conversion, as shown in run no. 8-9 in Table I. The latter result may be caused by the radical copolymerization of vinyl monomers and the subsequent ringopening reaction to form the cross-linking unit as follows
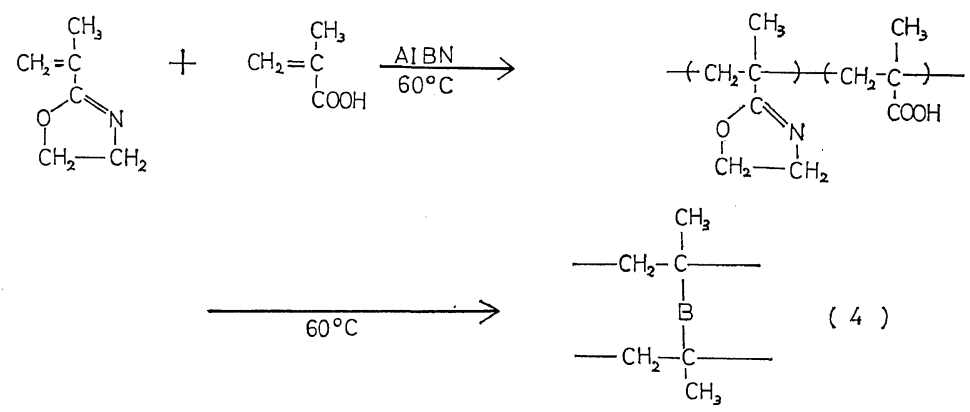

where $\mathrm{B}=-\mathrm{CNHCH}_{2} \mathrm{CH}_{2} \mathrm{OC}-$<smiles>O=CCCCCCO</smiles>

(B) Cationic Cross-linking Reaction of Poly(2Isopropenyl-2-oxazoline)

The present authors reported in a previous paper $^{11}$ that the oxazolinium perchlorate (POP) prepared from 2-phenyl-2-oxazoline and perchloric acid showed an excellent catalytic activity in the cationic polymerization of 2-oxazolines. As shown in run no. 1 in Table II, the cationic

Table II. The cross-linking reaction of poly(2-isopropenyl-2-oxazoline) by cationic ring-opening polymerization ${ }^{a}$

\begin{tabular}{|c|c|c|c|c|c|}
\hline Run no. & Oxazoline & Calalyst & $\frac{\text { Catalyst }^{b}}{\text { Monomer }}$ & Appearance & $\begin{array}{l}\text { Gel fraction, } \\
\text { wt } \%\end{array}$ \\
\hline 1 & Poly-IPOZ ${ }^{\mathrm{c}}$ & $\mathrm{POPe}^{\mathrm{e}}$ & 0.010 & Gel & 25 \\
\hline 2 & - & Poly-salt ${ }^{f}$ (partial) & 0.106 & Gel & - \\
\hline 3 & Poly-IPOZc & Poly-salt ${ }^{f}$ (partial) & 0.010 & Gel & 4.1 \\
\hline 4 & Poly-IPOZ & Poly-salt ${ }^{f}$ (complete) & 0.010 & Gel & - \\
\hline 5 & $\mathrm{PhOZ}^{\mathrm{d}}$ & Poly-saltg (complete) & 0.204 & Sol & $0.9^{\mathrm{h}}$ \\
\hline
\end{tabular}

a Reactions were carried out in $N, N$-dimethylacetamide media at $150^{\circ} \mathrm{C}$ for $2 \mathrm{hr}$.

b The initial molar ratio of catalyst to the oxazoline group in polymer or monomer.

c Poly-IPOZ is poly(2-isopropenyl-2-oxazoline) resulting from the radical polymerization of 2-isopropenyl2-oxazoline.

d $\mathrm{PhOZ}$ is 2-phenyl-2-oxazoline.

- POP is the perchlorate salt of 2-phenyl-2-oxazoline.

${ }^{f}$ and $g$ The Poly-salts denote the oxazolinium perchlorate of Poly-IPOZ; the partial one is $11 \mathrm{~mol} \%$, the complete $100 \mathrm{~mol} \%$ (see the section of EXPERIMENTAL).

h The conversion was $85 \mathrm{wt} \%$. 


\section{T. Kagiya and T. Matsuda}

polymerization of Poly-IPOZ regarded as polyfunctional oxazoline monomer initiated by POP catalyst gave an insoluble, infusible cross-linked polymer at $150^{\circ} \mathrm{C}$. Similarly, either cationic polymerization of Poly-IPOZ initiated with the complete or partial perchlorate of Poly-IPOZ
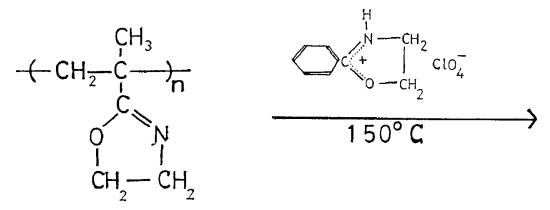

where E denotes $\underset{\mathrm{O}}{\mathrm{C}-\mathrm{N}}\left\langle\mathrm{CH}_{2} \ldots\right.$.

On the other hand, the cationic polymerization of 2-phenyl-2-oxazoline initiated by the complete perchlorate of Poly-IPOZ gave a white powdery product (run no. 5 in Table II). The product was soluble in chloroform and methanol, but insoluble in diethyl ether and $n$-hexane. The infrared spectrum of the product was similar to that of $N$-benzoyl polyethylenimine prepared from 2-phenyl-2-oxazoline with the use of POP catalyst. These facts may indicate that the product is mainly a graft polymer of Poly-IPOZ backbone with a branched chain of $N$-benzoyl polyethylenimine.

Cationic Selective Polymerization of 2-Isopropenyl2-oxazoline

The infrared spectrum of the white powdery solid obtained from IPOZ and perchloric acid showed the characteristic absorptions of the oxazoline heterocycle, which were slightly shifted from the original peaks (Figure 4). The imino $(\mathrm{C}=\mathrm{N})$ stretching vibration shifted toward a higher wave length $\left(\Delta \nu_{\mathrm{C}=\mathrm{N}}=\nu_{\text {free }}-\nu_{\mathrm{complexed}}=\right.$ $5 \mathrm{~cm}^{-1}$ ), whereas the ether stretching vibration shifted toward a lower wave length $\left(\Delta \nu_{\mathrm{C}_{-} \mathrm{O}}=\right.$ $\left.-11 \mathrm{~cm}^{-1}\right)$. The elementry analysis indicated that the product was an equimolar compound of IPOZ and perchloric acid. From these results, the product is identified as the oxazolinium salt of monomer and perchloric acid as follows (see EXPERIMENTAL section) gave cross-linked polymers, as shown in run no. 2-5 in Table II. From these observations, it is concluded that these cationic polymerizations of Poly-IPOZ lead to a network polymer possessing the following tertiary amide linkage as a cross-linking unit.

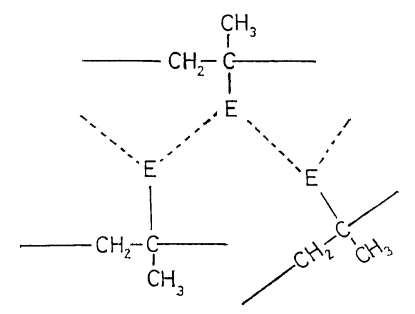

(5)

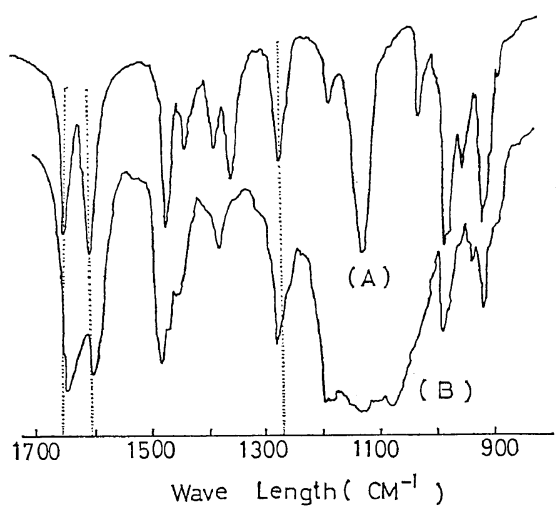

Figure 4. The infrared spectrum of the oxazolinium perchlorate of 2-isopropenyl-2-oxazoline: (A) 2-isopropenyl-2-oxazoline (IPOZ); (B) the perchlorate salt of the IPOZ monomer.<smiles>CC(C)C1NCCO1</smiles>

where the change of the bonding state by the quaternization in the oxazoline heterocycle brought about the bond-loosening of the imino linkage and the bond-strengthening of the ether linkage as described in a previous paper. ${ }^{11}$

The solution polymerization of IPOZ in $N, N$-dimethylacetamide with the use of the oxa- 
zolinium perchlorate $\left(\mathrm{IPOZ}-\mathrm{HClO}_{4}\right)$ of monomer produced a cross-linked or three dimensional structure in the absence of a radical inhibitor, whereas a white powdery solid soluble in chloroform and methanol was formed in the presence of hydroquinone (run no. $1-5$ in Table II). As shown in Figure 1 [(A) and (C)], the infrared spectrum of the product obtained in the presence of hydroquinone displayed characteristic absorptions at $1720 \mathrm{~cm}^{-1}$ and $1630 \mathrm{~cm}^{-1}$ ascribable to the carbonyl and carbon-carbon double bonds, respectively. The disappearance of the characteristic peaks of oxazoline heterocycle $\left(\nu_{\mathrm{C}=\mathrm{N}}\right.$ at $1655 \mathrm{~cm}^{-1}, \nu_{\mathrm{C}-\mathrm{O}}$ at 1278 and $1137 \mathrm{~cm}^{-1}$, and ring skeletal vibration at $900-1000 \mathrm{~cm}^{-1}$ ) indicates the ring-opening of the oxazoline heterocycle. The infrared spectrum of the product is similar to that of $N$-methacryloylethylenimine [monomeric unit analogous to $N$-methacryloyl polyethylenimine; Figure 1 (D)].

The NMR spectrum of the product showed the proton signals at $3.8 \tau$ and $4.5 \tau$ assignable to $\beta$-protons in the methacryloyl group, a broad peak at $6.8 \tau$ to $\mathrm{N}^{-\mathrm{CH}_{2}}$ and signals at $8.0 \tau$ to methyl protons (Figure 2). The results of the infrared spectrum and the relative ratio of integration of peaks in the NMR spectrum shows that the product is a linear polymer $(N$ methacryloyl polyethyenimine) with a polymerizable methacryloyl group as a pendant side chain as follows.

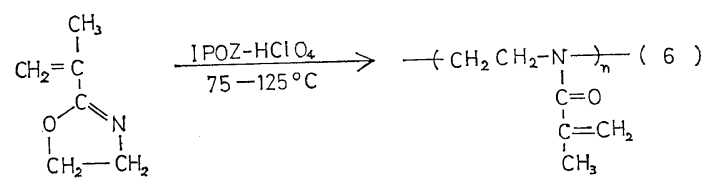

The polymer yield and the reduced viscosity of $0.25-\%$ chloroform solution of polymer at $35^{\circ} \mathrm{C}$ increases with an increase in the degree of conversion as shown in Table III. These facts may suggest that this selective cationic polymerization proceeds successively through the same mechanism as the cationic polymerization of 2-phenyl-2-oxazoline. ${ }^{11}$ With the use of the complexes of monomer and stannic chloride or boron trifluoride, which will be identified in a subsequent paper, ${ }^{11}$ the cationic polymerization of IPOZ also gave soluble linear polymers as shown in Table III.
Table III. The cationic polymerization of 2-isopropenyl-2-oxazoline initiated by the oxazolinium perchlorate or the complex of monomer and Lewis acid $^{a}$

\begin{tabular}{|c|c|c|c|c|c|c|}
\hline $\begin{array}{l}\text { Run } \\
\text { no. }\end{array}$ & Catalyst & $\begin{array}{l}\text { Reac- } \\
\text { tion } \\
\text { temp, } \\
{ }^{\circ} \mathrm{C}\end{array}$ & $\begin{array}{c}\text { Reac- } \\
\text { tion } \\
\text { time, } \\
\text { min }\end{array}$ & $\begin{array}{l}\text { Yield, } \\
\text { wt \% }\end{array}$ & $\frac{1}{6} \eta_{\mathrm{sp}} / c^{\mathrm{e}}$ & $\begin{array}{l}\text { Melting } \\
\text { point, } \\
{ }^{\circ} \mathrm{C}\end{array}$ \\
\hline 1 & $\mathrm{IPOZ}^{-\mathrm{HClO}_{4}}{ }^{\mathrm{b}}$ & 70 & 60 & 8 & 0.11 & 160 \\
\hline 2 & IPOZ- & 100 & 30 & 21 & 0.18 & 175 \\
\hline 3 & IPOZ- & 125 & 30 & 39 & 0.22 & $\begin{array}{l}200 \\
(\mathrm{dec})\end{array}$ \\
\hline 4 & IPO & 70 & 60 & 18 & - & 181 \\
\hline 5 & $(\mathrm{IPOZ})_{2} \mathrm{SnCl}_{4}{ }^{\mathrm{d}}$ & 70 & 60 & 10 & - & - \\
\hline
\end{tabular}

a $2.00 \mathrm{~g}$ of monomer, $3.0 \mathrm{ml}$ of $N, N$-dimethylacetamide as solvent and $1 \mathrm{~mol} \%$ of hydroquinone to monomer as radical inhibitor were used.

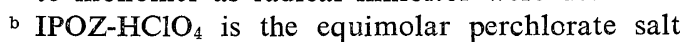
of monomer.

c $\mathrm{IPOZ}_{-\mathrm{BF}_{3}}$ is the equimolar complex of monomer and boron trifluoride.

d $(\mathrm{IPOZ})_{2} \mathrm{SnCl}_{4}$ is the 2:1 complex of monor and stannic chloride.

e The specific viscosity of $0.25-\%$ chloroform solution at $35^{\circ} \mathrm{C}$.

The polymers thus obtained became gradually yellow on exposure to air and light and transformed to insoluble polymers. In addition, the gelation was observed immediately in the radical polymerization of $N$-methacryloyl polyethylenimine with $\alpha, \alpha^{\prime}$-azobisisobutyronitrile as an initiator in an $N, N$-dimethylacetamide media at $60^{\circ} \mathrm{C}$. The above facts may indicate that the methacryloyl group in polymer susceptible to a radical initiator leads to cross-linked, insoluble polymers as follows

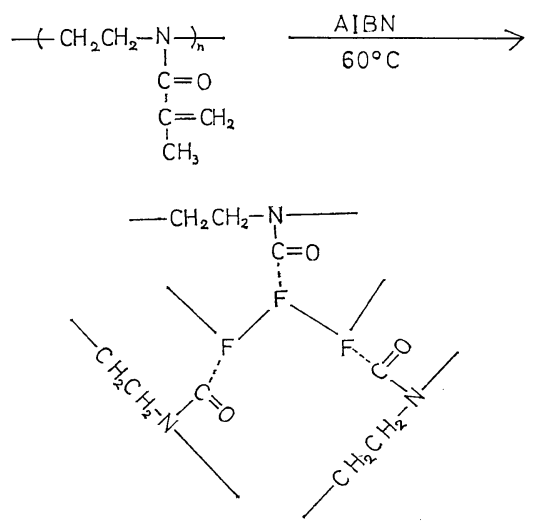

(7) 


\section{T. KagiYa and T. Matsuda}

where $\mathrm{F}$ denotes $-\mathrm{CH}_{2}-\stackrel{\stackrel{!}{\mathrm{C}}-}{\mathrm{CH}_{3}}$

\section{Mechanism of Cationic Selective Polymerization}

As shown in the result of the infrared spectrum of IPOZ- $\mathrm{HClO}_{4}$ as an initiator, the quaternization of the $\mathrm{N}$ atom in the oxazolinium heterocycle brought the change of the bonding state and facilitated the nucleophilic attack of the incoming monomer on the oxazolinium ion in which the positive charge was delocalized in the heterocycle. The initiation and propagation reactions of the ring-opening polymerization ${ }^{1,2,5,11}$ of IPOZ are considered to proceed through the nucleophilic attack of monomer on the 5-position in the oxazolinium ion as schematically represented in eq 8 and 9.
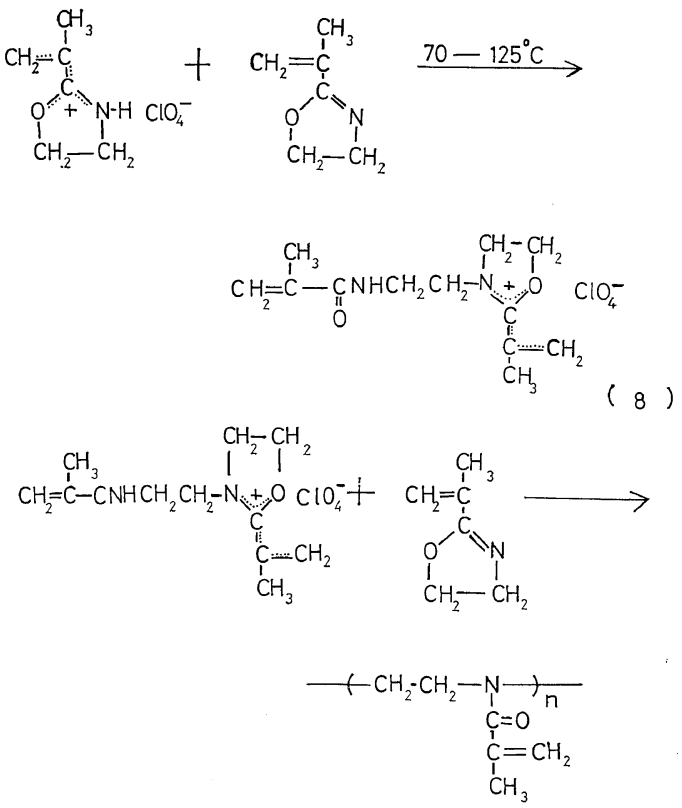

(g)

The radical copolymerization of IPOZ and styrene gives the copolymerization parameter of $Q=0.81$ and $e=0.35$ which will be described in a subsequent paper. ${ }^{12}$ This result indicates that the oxazoline group acts as an electron-withdrawing group toward the isopropenyl group, as does the methyl ester group in the methyl methacrylate molecule. ${ }^{13}$ On the other hand, the polymerizability of the residual group in a linear polymer obtained by the cationic polymerization of IPOZ is considered to be similar to that of $N$-methacrylamide derivatives susceptible to an anionic initiator, but unsusceptible to a cationic initiator. ${ }^{14}$ The reason why the isopropenyl group in IPOZ monomer and the methacryloyl group in the $N$-methacryloyl polyethylenimine are not susceptible to cationic polymerization may be due to the electrondeficient character of these polymerizable groups with a considerable positive $e$-value.

Acknowledgement. The authors wish to express their sincere thanks to Mr. Hiroshi Hatta for the skilful technical assistance in carrying out the experiments.

\section{REFERENCES}

1. T. Kagiya, S. Narisawa, T. Manabe, and K. Fukui, J. Polym. Sci., Part B, 4, 441 (1966).

2. D. A. Tomalia and D. P. Sheetz, ibid., Part $A$, 4, 2253 (1966).

3. W. Seeliger and W. Thier, Angew. Chem., 78, 613 (1966).

4. T. G. Bassiri, A. Levey, and M. Litt, J. Polym. Sci., Part B, 5, 871 (1967).

5. T. Saegusa, H. Ikeda, and H. Fujii, Polymer J., 3, 176 (1972).

6. T. Kagiya, S. Narisawa, T. Maeda, and K. Fukui, Kogyo Kagaku Zasshi (J. Chem. Soc. Japan, Ind. Chem. Sect.), 69, 732 (1966).

7. N. Watanabe, Y. Sasakibara, and N. Uchino, Kogyo Kagaku Zasshi (J. Chem. Soc. Japan, Ind. Chem. Sect.), 72, 137 (1969).

8. S. S. Skorokhodov, S. G. Ershova, N. V. Mikhailov, and A. A. Vansheidt, Zh. Obshch. Khim., 31, 3626 (1961); Chem. Abstr., 57, 8555f (1962).

9. E. M. Fry, J. Org. Chem., 15, 802 (1950).

10. T. Kagiya, S. Narisawa, T. Manabe, and K. Fukui, J. Polym. Sci., Part B, 4, 257 (1966).

11. T. Kagiya and T. Matsuda, J. Macromol. Sci.Chem., A5, 1277 (1971).

12. T. Kagiya, T. Matsuda, and K. Zushi, $J$. Macromol. Sci.-Chem., in contribution.

13. J. Bandrup and E. H. Immergut, Ed., "Polymer Handbook,', Interscience, New York, N.Y. 1966; G. E. Ham, Ed., "Copolymerization," High Polymers, Vol. XVIII, Interscience, New York, N.Y., 1964.

14. C. E. Schildknecht, Ind. Eng. Chem., 50, 107 (1958); A. M. North and A. M. Scallan, Polymer, 5, 447 (1964). 